\title{
Effect of different pupil to eye size ratios on tonic immobility in chickens
}

\author{
GREGG J. GAGLIARDI, GORDON G. GALLUP, JR. and JAMES L. BOREN \\ State University of New York, Albany, New York 12222
}

\begin{abstract}
Seven simulated eyes with varying pupil size to eye ratios were tested for their effects on the duration of tonic immobility. A pair of eyes with a ratio of approximately $11 / 20 \mathrm{~mm}$ was the only configuration which produced reliable increases in response duration. The results were discussed as they relate to the possible role of eye contact in predator-prey encounters.
\end{abstract}

Tonic immobility (TI) appears to function as the terminal response in a series of distance-dependent predator defenses (Ratner, 1967; Sargeant \& Eberhardt, 1975). The response, which is produced by some form of physical restraint, occurs in a wide variety of species and is characterized by a catatonic-like state of physical immobility and muscle hypertonicity. Attempts to produce TI in the laboratory eventuate in immobility episodes that vary in duration from a few seconds to several hours.

Among the most potent agents for increasing the duration of TI are stimuli which are thought to produce fear (Gallup, 1974). Prominent in this list are stimulus characteristics of potential predators. In a series of studies, it has been shown that (a) the opportunity to view a stuffed hawk or a human experimenter increases the duration of TI in chickens (Gallup, Cummings, \& Nash, 1972; Gallup, Nash, Donegan, \& McClure, 1971) and lizards (Edson \& Gallup, 1972; Gallup, 1973), and that (b) the effects of simulated predation on TI are due almost exclusively to the visibility of the predator's eyes. Of such singular importance are eyes in sustaining TI that merely suspending artificial glass eyes over immobilized chickens (Gallup, Nash, \& Ellison, 1971) or crabs (O'Brien \& Dunlap, 1975) results in a marked increase in response duration.

The preceding findings, when considered together, strongly suggest that eye contact plays a powerful and fundamental role in the maintenance of tonic immobility. A logical next step would be an attempt to determine which feature(s) of such eyes is critical for sustaining the reaction. O'Brien and Dunlap (1975) found that artificial eyes potentiated TI in crabs, but eyes of different sizes all yielded comparable effects. One likely candidate for remaining investigation is the size of the pupil relative to the rest of the eye.

Requests for reprints should be sent to G. G. Gallup, Jr., Department of Psychology, State University of New York at Albany, Albany, New York 12222.

\section{METHOD}

\section{Subjects}

The subjects were 86 straight-run, Production Red chickens (Gallus gallus) obtained from a local hatchery at 1-2 days of age. All birds were housed in commercial brooders and maintained on artificial light for $14 \mathrm{~h} / \mathrm{day}$. Purina Chick Chow (Growena) and water were continuously available during rearing.

\section{Apparatus}

The apparatus consisted of an upright stand, fitted with a pair of $1.27-\mathrm{cm}$ wooden dowels which could be suspended over an immobilized bird. Small magnets were attached to the ends of the dowels and provided a means by which stimulus materials could be attached and replaced.

The stimulus materials consisted of seven pairs of circular paper eyespots measuring $2 \mathrm{~cm}$ in diam, with metal washers glued to the back of each eye to allow attachment to the dowels. Eyespot patterns were prepared from commercial yellow and black construction paper, and differed only in the size of the central black circular spot. Ratios of the black spot to its yellow border were $0 / 20,2 / 20,6 / 20,11 / 20,15 / 20,19 / 20$, and $20 / 20 \mathrm{~mm}$ (see Figure 1). The entire inside face of the upright stand was painted flat gray to provide contrast between the eyespot patterns and the overhead surround.

The apparatus was placed on a table in a separate testing room. The dowels, complete with at tached eyespots, were suspended approximately $22 \mathrm{~cm}$ from the table. Stopwatches were used to time response duration.

\section{Procedure}

To insure for a low level of responsiveness on the test day, and in an'effort to reduce intersubject variability, all birds were habituated prior to testing (Gallup, Nash, \& Wagner, 1971). Habituation began when the birds were 3 weeks of age and consisted of five attempts to elicit TI for 3 consecutive days. Tonic immobility was induced by restraining a bird on its right side and applying gentle pressure with both hands for $15 \mathrm{sec}$. On habituation trials, each immobility response was artificially terminated by gentle prodding following $30 \mathrm{sec}$. The intertrial interval was $60 \mathrm{sec}$, and began when a bird righted itself or when the experimenter terminated the reaction.

On the day following the last habituation trial, groups of eight birds were randomly assigned to one of the seven eyespot conditions and tested individually for tonic immobility. Each bird was carried to a nearby experimental room in a cardboard box, placed on a table beneath the suspended eyespots, and immobilized as before. Tonic immobility was measured from the time the experimenter released the bird until it righted itself. 


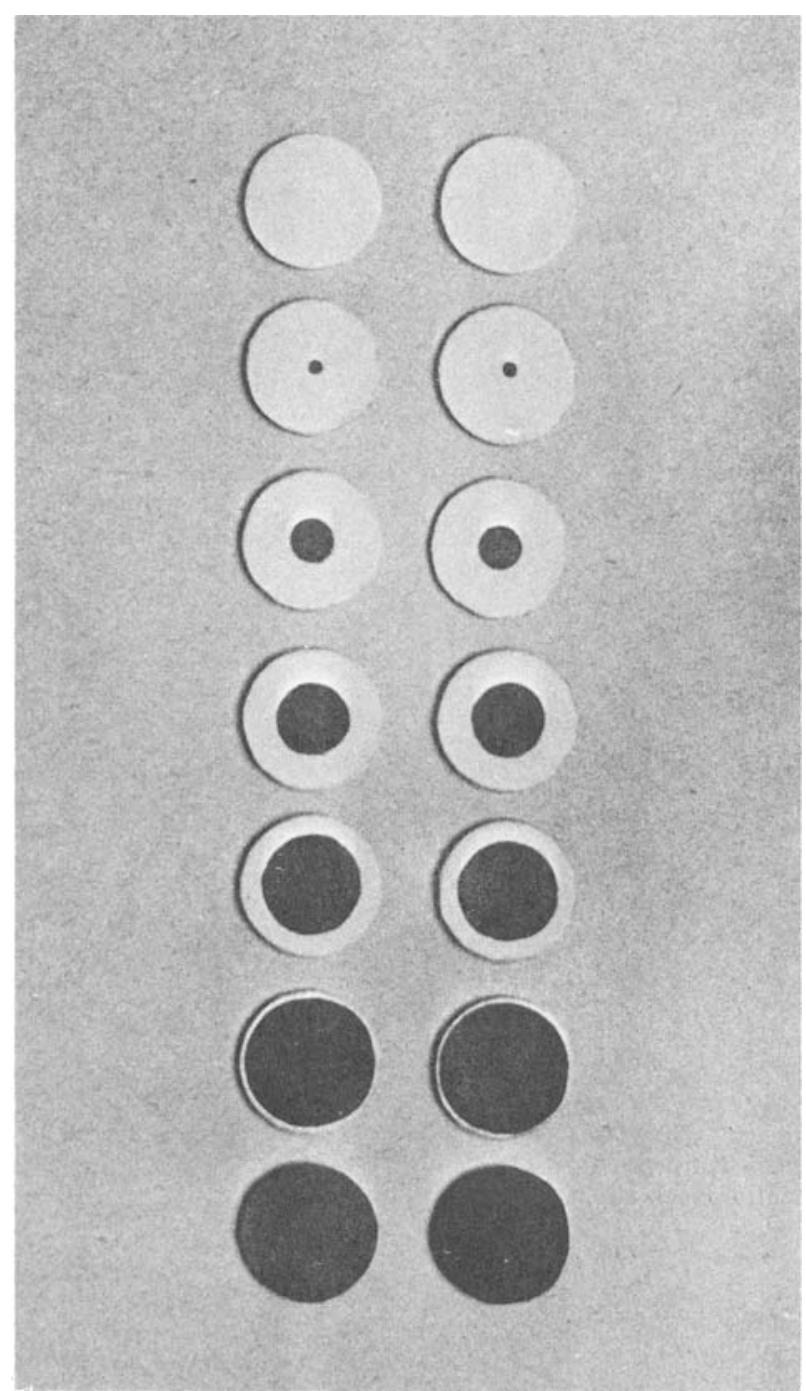

Figure 1. Photograph of the different eyespot patterns used as stimulus materials.

Birds failing to show TI following the first induction were given up to five consecutive trials. Several weeks later, an additional 30 birds were maintained and habituated as before, and tested under one of the middle three eyespot patterns $(6 / 20,11 / 20$, $15 / 20$ ), thus increasing the sample sizes for these three groups to 18 subjects each.

\section{RESULTS}

Due to several unusually high scores, the data were Winsorized (Dixon \& Tukey, 1968; Winer, 1971). Winsorization was accomplished by eliminating the highest and lowest scores from each group and replacing them with the next highest and lowest scores, which entailed the loss of $1 \mathrm{df}$ from the error term for each substituted score. The Winsorized mean duration of TI for each of the eyespot patterns is presented in Figure 2. As can be seen, a pupil to eye ratio of $11 / 20$ appeared to be the most effective pattern. A one-way analysis of variance revealed a significant between-groups effect $(F=2.83, \mathrm{df}=6 / 65, \mathrm{p}<.025)$. Subsequent breakdown of the between-groups effect by an orthogonal comparison revealed that Group 11/20 was significantly different from the average of all other groups $(F=14.30, d f=1 / 65, p<.001)$. In addition, a second orthogonal comparison between Group 6/20, the lowest group, and 15/20, the second highest group, was nonsignificant. All other comparisons among group means, other than $11 / 20$, were likewise nonsignificant.

\section{DISCUSSION}

The present findings correspond with previous work on the effect of artificial eyes on TI in chickens (Gallup et al., 1971) by showing that simulated eye contact potentiates immobility. Of special significance was the observation that a pair of eyes with a pupil to eye ratio of $11 / 20 \mathrm{~mm}$ was the only effective pattern in this sample. This finding suggests that what constitutes an "eye" for the chicken may be remarkably specific. While there was no apparent gradient centering around the $11 / 20$ eyes, this does not rule out the possibility of a gradient between the two neighboring eyes of $6 / 20$ and $15 / 20$. Indeed, the present finding of only one effective pattern may only represent the investigator's underestimation of the chicken's ability to discriminate eyespot patterns.

Blest (1957) has demonstrated that eyespots on the wings of Lepidoptera are effective deterrents to a variety of avians that prey on insects. He suggested that these patterns might represent the result of evolutionary pressure to develop eyespots that mimicked the eyes of the insect predator's predator. It may be more than coincidental that informal measurements in our laboratory of the eyespot patterns on several members of one species of Lepidoptera (Automeris io) conformed well to the proportions of the 11/20 eye used in this study. Perhaps such selectivity in response to eye-like configurations constitutes the basis for the evolutionary development of such intricately developed patterns.

Although the pair of $11 / 20$ eyes was effective in potentiating tonic immobility, it is important to acknowledge that the duration scores under this condition were appreciably smaller than those reported previously for artificial glass eyes (Gallup, Nash, \& Ellison, 1971). There are a number of possible reasons for these differences. The eyespot patterns used in the present study were two- rather than three-dimensional and were composed of

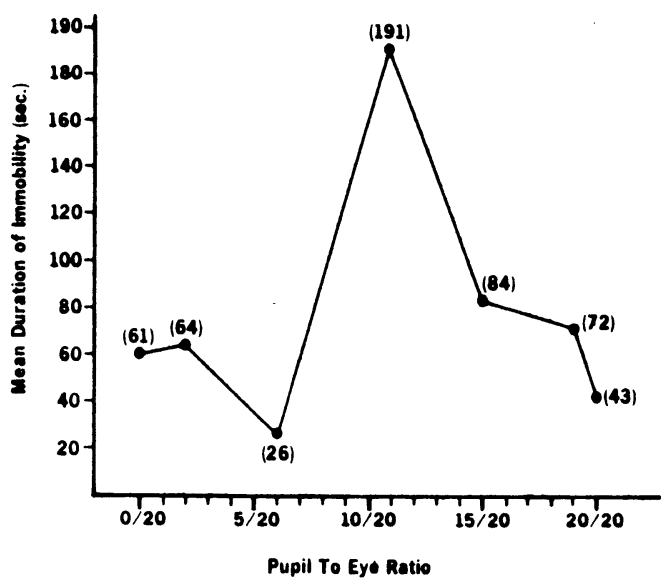

Figure 2. Average duration of tonic immobility as a function of different pupil to eye size ratios in millimeters. 
construction paper, which lacked the reflective properties of real eyes or glass. It is interesting to note that many of the naturally occurring eyespots on insects have incorporated a tiny white dot which mimics a highlight associated with reflected light from real eyes.

A more general consideration might be directed toward the mechanism(s) whereby the presence of eyes serves to enhance tonic immobility. Following immobility onset, the ability of an organism to selectively attend to its predator's eyes may possess considerable survival value. Such attention may allow the prey to accurately gauge the attention of the predator, and thereby provide important information about potential escape opportunities. Naturalistic observations of predation on ducks by red foxes (Sargeant \& Eberhardt, 1975) provide some support for this suggestion. These investigators found that ducks often exhibit tonic immobility when captured by foxes, and noted that immobilized "ducks appeared alert and aware of escape opportunities. Visual and possibly auditory cues from nearby foxes appeared to delay recovery (sustain TI) . . . they of ten lifted their heads slowly and appeared to look about before standing up. If approached by foxes, they slowly lowered their heads again" (p. 111). As Gallup (1974) has suggested, experimental manipulation of escape opportunities might provide an important source of information concerning factors responsible for immobility maintenance in predator-prey interactions.

\section{REFERENCES}

Blest. A. D. The function of eyespot patterns in the Lepidoptera. Behaviour. 1957. 11, 209-256.

Dixon. W. J.. \& TukEY. J. W. Approximate behavior of the distribution of Winsorized $t$ (Trimming/Winsorization 2). Technometrics. 1968, 10, 83-98.

Edson. P. H.. \& Gallup. G. G.. JR. Tonic immobility as a tear response in lizards (Anolis carolinensis). Psychonomic Science. 1972. 26. 27-28.
GalluP. G. G., JR. Simulated predation and tonic immobility in lizards (Anolis carolinensis). Copeia, 1973, 3. 623-624.

Gallup. G. G.. JR. Animal hypnosis: Factual status of a tictional concept. Psychological Bulletin. 1974, 81. 836-853.

Gallup, G. G., JR., Cummings, W. H., \& Nash, R. F. The experimenter as an independent variable in studies of animal hypnosis in chickens (Gallus gallus). Animal Behaviour. 1972, 20. 166-169.

Gallup. G. G.. JR., Nash, R. F., Donegan. N. H., \& McClune, M. K. The immobility response: A predatorinduced reaction in chickens. Psychological Record. 1971. 21. $513-519$.

Gailip. G. G.. JR.. Nash. R. F.. d Ellison, A. L.. JR. Tinic immobility as a reaction to predation: Artificial "No as a fear stimulus for chickens. Psychonomic Sirince. 1971, 23. 74-80.

Gallup. G. G.. JR.. Nash. R. F.. \& Wagner, A. M. The tonic immobility reaction in chickens: Response characteristics and methodology. Behavior Research Methods \& Instrumentation. 1971, 3. 237-239.

O'Brien. T. J.. \& Dunlap. W. P. Tonic immobility in the blue crab: Its relation to threat of predation. Journal of Comparative and Physiological Psychology' 1975. 89. 86-94.

Ratner. S. C. Comparative aspects of hypnosis. In J. E. Gordon (Ed.). Handbook of clinical and experimental hypmosis. New York: Macmillan. 1967.

Sargeant. A. B.. \& Eberhardt. L. E. Death feigning by ducks in response to predation by red foxes (Vulpes fulva). American Midland Naturalist, 1975. 94. 108-119.

WINER. B. J. Statistical principles in experimental design. New York: McGraw-Hill. 1971.

(Received for publication March 26. 1976.) 